\title{
Phosphatidylserine-dependent ingestion of apoptotic cells promotes TGF- $\beta 1$ secretion and the resolution of inflammation
}

\author{
Mai-Lan N. Huynh, ${ }^{1}$ Valerie A. Fadok, ${ }^{2}$ and Peter M. Henson ${ }^{2}$ \\ ${ }^{1}$ Department of Pulmonary and Critical Care Medicine, University of Colorado Health Sciences Center, Denver, Colorado, USA \\ ${ }^{2}$ Program in Cell Biology, Department of Pediatrics, National Jewish Medical and Research Center, Denver, Colorado, USA
}

Address correspondence to: Mai-Lan N. Huynh, National Jewish Medical and Research Center, D505, 1400 Jackson Street, Denver, Colorado 80206, USA. Phone: (303) 398-1282; Fax: (303) 398-1381; E-mail: huynhm@njc.org.

Received for publication October 24, 2000, and accepted in revised form October 30, 2001.

Ingestion of apoptotic cells in vitro by macrophages induces TGF- $\beta 1$ secretion, resulting in an antiinflammatory effect and suppression of proinflammatory mediators. Here, we show in vivo that direct instillation of apoptotic cells enhanced the resolution of acute inflammation. This enhancement appeared to require phosphatidylserine (PS) on the apoptotic cells and local induction of TGF- $\beta 1$. Working with thioglycollate-stimulated peritonea or LPS-stimulated lungs, we examined the effect of apoptotic cell uptake on TGF- $\beta 1$ induction. Viable or opsonized apoptotic human Jurkat $T$ cells, or apoptotic PLB-985 cells, human monomyelocytes that do not express PS during apoptosis, failed to induce TGF- $\beta 1$. PS liposomes, or PS directly transferred onto the PLB-985 surface membranes, restored the TGF- $\beta 1$ induction. Apoptotic cell instillation into LPS-stimulated lungs reduced proinflammatory chemokine levels in the bronchoalveolar lavage fluid (BALF). Additionally, total inflammatory cell counts in the BALF were markedly reduced 1-5 days after apoptotic cell instillation, an effect that could be reversed by opsonization or coinstillation of TGF- $\beta 1$ neutralizing antibody. This reduction resulted from early decrease in neutrophils and later decreases in lymphocytes and macrophages. In conclusion, apoptotic cell recognition and clearance, via exposure of PS and ligation of its receptor, induce TGF- $\beta 1$ secretion, resulting in accelerated resolution of inflammation.

J. Clin. Invest. 109:41-50 (2002). DOI:10.1172/JCI200211638.

\section{Introduction}

Apoptosis, or programmed cell death, is a critical process in natural tissue homeostasis and results in immediate removal of the dying cell, either by neighboring cells or by professional phagocytes such as macrophages and dendritic cells. Apoptotic cells undergo characteristic surface membrane changes that are recognized by receptors present on the phagocytes. Most recently, the aminophospholipid phosphatidylserine (PS) has been implicated as an important ligand for clearance (1). PS is normally found on the inner leaflet of the asymmetric surface membrane bilayer and is translocated to the outer leaflet by a phospholipid scramblase that is activated by protein kinase $\mathrm{C} \delta(\mathrm{PKC} \delta$ ) (2). Concurrent inactivation of the aminophospholipid translocase prevents PS returning to the inner leaflet, leaving PS expressed on the apoptotic cell's surface (3). Recognition of surface PS by a newly cloned receptor (the PSR) that is present on the phagocyte initiates uptake of the apoptotic cell (4). Other described apoptotic cell recognition systems have been recently reviewed $(5,6)$ and include $\alpha_{v} \beta_{3}$ integrin (vitronectin receptor) (7), class A scavenger receptor $(8,9)$, CD36 (class B scavenger receptor) (10), CD14 $(11,12)$, and collectin receptors $(13)$.

Engulfment of these apoptotic cells is thought not only to remove them from the tissues but also to pro- vide protection from local damage resulting from release or discharge of injurious or proinflammatory contents $(14,15)$. We have also shown that, in addition to its proposed role in removing cells before they undergo lysis, in vitro ingestion of apoptotic cells actively suppressed production of proinflammatory growth factors, cytokines, chemokines (e.g., GM-CSF, $\mathrm{MIP}_{2}$, IL- $1 \alpha, \mathrm{KC}, \mathrm{IL}-8$, and TNF- $\alpha$ ), and eicosanoids $(16,17)$. This downregulation of proinflammatory mediators in response to apoptotic cells has been shown in human monocyte-derived macrophages, murine macrophage cell lines (RAW264.7 and J774), and bone marrow-derived macrophages, as well as fibroblasts and mammary epithelial cells $(4,16,17)$. The suppressive effect was largely (but not exclusively) inhibited by TGF- $\beta 1$ neutralizing antibodies and reproduced by exogenous TGF- $\beta 1$, implicating a major role for this anti-inflammatory agent in the reduction of these proinflammatory mediators.

The TGF- $\beta$ family consists of closely related isoforms (TGF- $\beta 1,-\beta 2$, and $-\beta 3$ in mammals) that are potent multifunctional regulating factors modulating diverse cellular activities (18-20). TGF- $\beta 1$ causes growth inhibition and differentiation of many cell types, regulation of immune and inflammatory response (21), and modulation of wound healing, ECM deposition (22), and cellular adhesion and migration (23). Most cells can 
express TGF- $\beta$ and its receptors. TGF- $\beta 1$ is secreted as a homodimer noncovalently bound to latency-associated peptide (LAP) (24); TGF-LAP may complex to latent TGF- $\beta$-binding protein-1 (LTBP-1) via disulfide bonds $(25,26)$. The active molecule needs to be released from LAP to become active and interact with its receptors, and a wide variety of activating processes have been described in vitro and in vivo $(27,28)$.

The potential anti-inflammatory effect of recognition and uptake of apoptotic cells may explain the quiet, noninflammatory nature of apoptotic cell removal during development and tissue remodeling. We have also questioned whether it is involved in the resolution of ongoing inflammatory responses, wherein apoptosis of inflammatory cells in the lesion (in particular, the short-lived neutrophils) leads to their removal by incoming mononuclear phagocytes (16), and consequent production of anti-inflammatory mediators such as TGF- $\beta$. To explore this hypothesis, deliberate instillation of apoptotic cells into sites of local inflammation in the lungs and peritonea was undertaken. Increased production of TGF- $\beta$ as well as enhanced resolution of the inflammation was the result. Furthermore, the experiments suggested a major role for the PSR in the TGF- $\beta$ production, which could be reproduced by instillation of PS-containing liposomes as well as of PS-expressing apoptotic cells.

\section{Methods}

Reagents. DMEM, RPMI 1640, HBSS, and PBS were purchased from Cellgro Mediatech Inc. (Herndon, Virginia, USA); X-vivo 10 medium was obtained from BioWhittaker Inc. (Walkersville, Maryland, USA); endotoxin-free FCS was from HyClone Laboratories (Logan, Utah, USA). LPS (from Escherichia coli 0111:B4) was from List Biological Laboratories (Campbell, California, USA); Brewer Thioglycollate Medium was from Difco Laboratories (Detroit, Michigan, USA); cycloheximide, PMSF, Avertin (2,2,2-tribromoethanol), and tert-amyl alcohol were from Sigma-Aldrich Company (St. Louis, Missouri, USA); Nonidet P-40 10\% (NP-40) was from Boehringer Mannheim GmbH (Mannheim, Germany). Polystyrene flasks and plates for tissue culture were from Becton Dickinson Labware (Franklin Lakes, New Jersey, USA). Chicken anti-rhTGF- $\beta 1$ IgY was obtained from R\&D Systems Inc. (Minneapolis, Minnesota, USA); Alexa 488 fluorescent-labeled goat anti-chicken IgG was from Molecular Probes Inc. (Eugene, Oregon, USA); mouse anti-human CD45 IgG1 and rat anti-mouse monoclonal anti-CD16/32 IgG2b were from Pharmingen (San Diego, California, USA). Brain PS and bovine liver L- $\alpha$-lecithin-phosphatidylcholine were obtained from Avanti Polar Lipids Inc. (Alabaster, Alabama, USA). Paraformaldehyde was obtained from Electron Microscopy Sciences (Fort Washington, Pennsylvania, USA). Popper animal feeding needles (22G, 1.5 in.) were obtained from Fisher Scientific Co. (Pittsburgh, Pennsylvania, USA). Normal saline (NS) and pentobarbital were from Abbott Laboratories (North Chicago, Illinois, USA).
Cells. Human T lymphocyte Jurkat cells were obtained from the American Type Culture Collection (Manassas, Virginia, USA), and human monomyelocyte PLB-985 cells were a gift from Christina Leslie (29). Cells were cultured in RPMI containing heat inactivated $10 \% \mathrm{FCS}$, $2 \mathrm{mM}$ L-glutamine, $100 \mathrm{U} / \mathrm{ml}$ penicillin, and $100 \mu \mathrm{g} / \mathrm{ml}$ streptomycin at $37^{\circ} \mathrm{C}, 5 \% \mathrm{CO}_{2}$. Apoptosis was induced by ultraviolet irradiation $(245 \mathrm{~nm})$ of Jurkat $T$ cells for 10 minutes and PLB-985 cells for 5 minute. Cells were incubated $2-4$ hours and used at $60-80 \%$ apoptosis (assessed morphologically by light microscopy of stained cytocentrifuged cells). Two hours after ultraviolet irradation, Jurkat $\mathrm{T}$ cells were opsonized by incubation with mouse anti-human CD45 IgG1 $(1 \mu \mathrm{g} / \mathrm{mil}-$ lion Jurkats) for 30 minutes at $4^{\circ} \mathrm{C}$.

Animals. ICR mice (8-10 weeks old, 25-30 g) were obtained from Harlan (Indianapolis, Indiana, USA). Females were used for peritoneal lavage, while both males and females were used for lung lavage. To induce peritoneal inflammation and harvest elicited macrophages, mice were stimulated with $1.5 \mathrm{ml}$ of intraperitoneal thioglycollate and harvested as described (30). For pulmonary inflammatory responses, animals were sedated with $0.3 \mathrm{ml}$ intraperitoneal Avertin (20 $\mathrm{mg} / \mathrm{ml})$. LPS $(20 \mu \mathrm{g}$ in $100 \mu \mathrm{l} \mathrm{NS})$ was instilled within 20 minutes, using a feeding needle inserted endotracheally above the carina (approximately 0.75 in. deep). The position was confirmed by respiratory fluctuation.

In vitro peritoneal macrophage assays. After 3 days, the mice were sacrificed by $\mathrm{CO}_{2}$ asphyxiation, and their peritonea were lavaged with $8 \mathrm{ml} \mathrm{HBSS}$ at $4^{\circ} \mathrm{C}$. Cells were pelleted at $250 \mathrm{~g}\left(10\right.$ minutes, $\left.4^{\circ} \mathrm{C}\right)$ and resuspended in DMEM at $1 \times 10^{6}$ cells per milliliter. The cells were plated at $3 \times 10^{6}$ macrophages per well in six-well polystyrene tissue culture plates and allowed to adhere for $30 \mathrm{~min}$ utes at $37^{\circ} \mathrm{C}$. Nonadherent cells were washed off with DMEM and remaining macrophages were cultured in 1-2 ml serum-free X-vivo 10 for experiments. Jurkat $\mathrm{T}$ cells were added at a ratio of three per macrophage; supernatants were harvested at 1-18 hours after cell addition and stored at $-70^{\circ} \mathrm{C}$.

In vivo assays. $40 \times 10^{6}$ viable or apoptotic cells in $1 \mathrm{ml}$ HBSS were injected into naive peritonea or peritonea stimulated with thioglycollate for 3 days. After $0.5-4$ hours of incubation, the peritoneum was lavaged; the cell pellets and supernatants were stored at $-70^{\circ} \mathrm{C}$ for ELISA assays. Peritoneal cells were lysed with $0.5 \%$ NP-40/1 mM PMSF/PBS $1 \times$ for 10 minutes at $4^{\circ} \mathrm{C}$ immediately prior to assay of TGF- $\beta 1$ by ELISA. In the lungs, $18 \times 10^{6}$ to $20 \times 10^{6}$ cells in $100 \mu$ HBSS were instilled endotracheally after 36-48 hours of LPS stimulation. At 1-2 hours after cell instillation, the animals were sacrificed with $10 \mathrm{mg}$ intraperitoneal pentobarbital and bronchoalveolar lavage (BAL) was carried out with $3 \mathrm{ml}$ HBSS. For the delayed assays, cells were instilled 24 hours after LPS, and $3 \mathrm{ml} \mathrm{BALF}$ was obtained at 1,3 , or 5 days after cell instillation. Cell counts and differentials were determined by light microscopy and the supernatant stored at $-70^{\circ} \mathrm{C}$ and assayed for cytokines 
and chemokines by ELISA. For anti-TGF- $\beta 1$ antibody inhibition experiments, $50 \mu$ lof goat anti-hrTGF- $\beta 1 \mathrm{IgG}$ $(200 \mu \mathrm{g} / \mathrm{ml}$; Santa Cruz Biotechnology Inc., Santa Cruz, California, USA) or normal goat IgG $(200 \mu \mathrm{g} / \mathrm{ml}$, Jackson ImmunoResearch Laboratories Inc., West Grove, Pennsylvania, USA) was coinstilled with $20 \times 10^{6}$ apoptotic Jurkat T cells in $100 \mu \mathrm{l}$ HBSS, or $100 \mu \mathrm{l}$ HBSS alone.

Lung histology. After lavage, the lungs were fixed with $1 \mathrm{ml}$ of $4 \%$ paraformaldehyde/PBS at $4^{\circ} \mathrm{C}$ for 4 hours, and embedded in paraffin. Paraffinized lung sections were placed on a $60^{\circ} \mathrm{C}$ heating block for 5-10 minutes and twice for 5 minutes in xylenes, followed by $100 \%$, $95 \%$, and $70 \%$ ethanol, and deionized H20 for twice for 5 minutes. Slides were then stained with hematoxylin and eosin (H\&E).

ELISA. TGF- $\beta 1$, mTNF- $\alpha, \mathrm{KC}, \mathrm{mMIP}_{2}$, mouse monocyte chemoattractant protein-1 (mMCP-1), and mIL-10 levels were measured by ELISA. Assays for TGF- $\beta 1$, mTNF- $\alpha, \mathrm{mMIP}_{2}$, and $\mathrm{mIL}-10$ were prepared from R\&D Systems Inc. reagents (TGF- $\beta 1$ : coating Ab MAB1835, detection Ab BAF240; mTNF- $\alpha$ : coating Ab 1221-00, detection $\mathrm{Ab}$ BAF410; MMIP $_{2}$ : coating Ab MAB452, detection Ab BAF452; and mIL-10: coating Ab MAB417, detection Ab BAF417). mMCP-1 ELISA was prepared from Pharmingen Mouse MCP-1 OPTEIA reagents. Quantikine M Mouse KC Immunoassay (R\&D Systems Inc.) was used to quantitate $\mathrm{KC}$ as directed by the manufacturer. Since the ELISA assay measures only active TGF- $\beta 1$, active TGF- $\beta 1$ was determined by directly measuring lavage fluids while total TGF- $\beta 1$ was measured after preactivation with acidification to $\mathrm{pH} 2-3$ for 60 minutes, and corrected to $\mathrm{pH} 6.5-7.5$ prior to the ELISA assay. Color development was assessed using the microplate autoreader (EL309) by Bio-Tek Instruments (Winooski, Vermont, USA). Data were analyzed using a $\log / \log$ curve fit option from Delta Soft 3 ELISA analysis software for the Macintosh (BioMetallics Inc., Princeton, New Jersey, USA).

Immunobistochemistry. Cell suspensions or cell culture on glass coverslips were fixed with $2 \%$ paraformaldehyde $/ 30 \%$ sucrose in PBS for 30 minutes at $37^{\circ} \mathrm{C}$. Cells were permeabilized with $0.02 \%$ Tween- 20 for 15 minutes at room temperature (RT) and Fc receptors blocked with rat anti-mouse CD16/CD32 IgG2b overnight at $4^{\circ} \mathrm{C}$. Cells were stained with chicken anti-rhTGF- $\beta 1$ IgY for 1 hour at RT, and then goat anti-chicken IgG Alexa 488 for 30 minutes at RT.

Liposomes. PS liposomes consisted of phosphatidylserine and phatidylcholine (PC). Phospholipids in chloroform/methanol (90:10) were dried under $\mathrm{N}_{2}$, resuspended in PBS, and sonicated for 3 minutes at $4^{\circ} \mathrm{C}$. Liposomes $(250 \mu \mathrm{M}$ total lipid in 100 $\mu \mathrm{l}$ PBS per mouse) were instilled endotracheally. Phospholipid transfer to insert PS into cell membranes was carried out as previously described (31). The same liposomes as described above were used at $10 \mu \mathrm{M}$ total lipids $/ 10^{6}$ cells. PS/PC or PC/PC liposomes were incubated with $40 \times 10^{6}$ PLB-985 cells in $6 \mathrm{ml}$ PBS once for 30 minutes at $37^{\circ} \mathrm{C}$. Cells were used immediately after washing with PBS and resuspending at $40 \times 10^{6}$ cells in $1 \mathrm{ml}$ PBS per mouse.

Statistical analysis. ANOVA with Tukey-Kramer and Dunnett tests honestly significant difference was carried out using JMP software (SAS Institute Inc., Cary, North Carolina, USA).

\section{Results}

TGF- $\beta 1$ production in macrophages harvested from inflamed sites. Macrophages lavaged from naive lungs and peritonea contained minimal TGF- $\beta 1$ when detected with goat anti-TGF- $\beta 1$ antibody, followed by fluorescent secondary donkey anti-goat IgG-FITC, and examined by confocal microscopy. After an inflammatory state was created at these sites (by instillation of either LPS

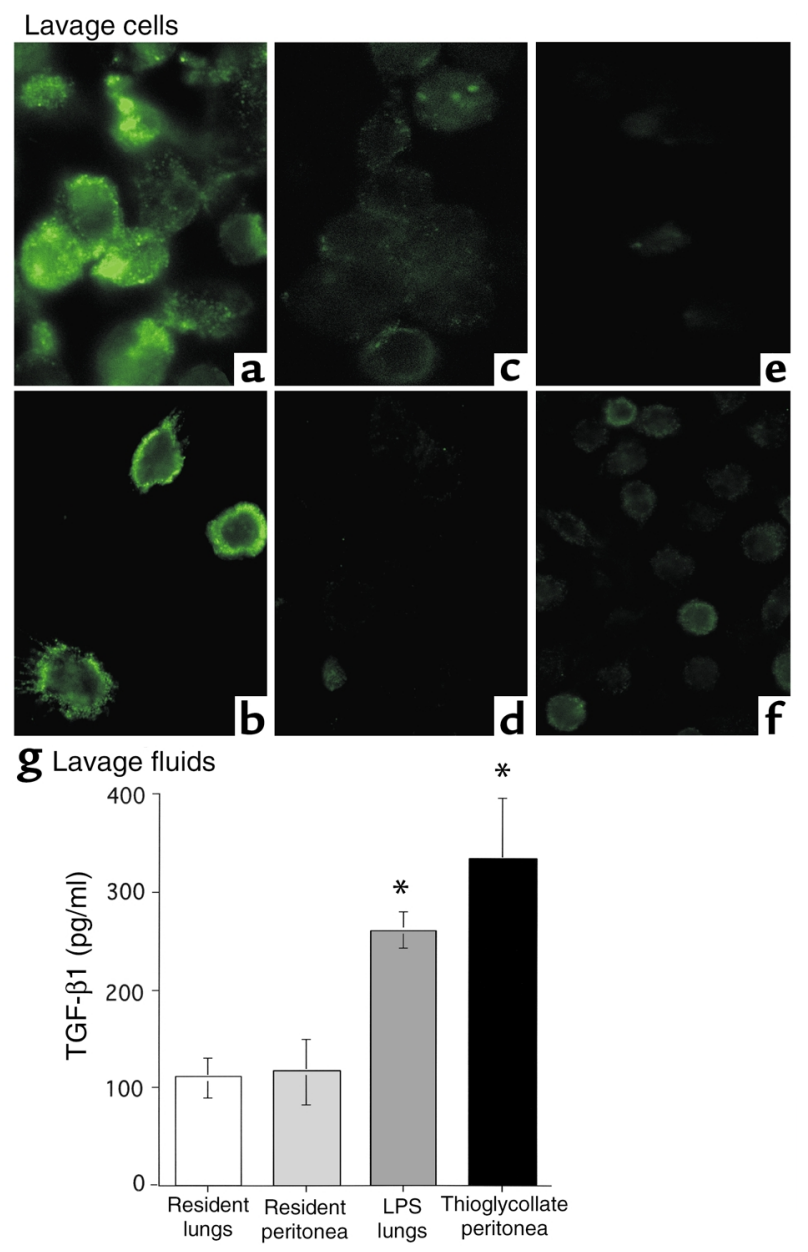

Figure 1

TGF- $\beta 1$ detection in fresh lavage. (a-f) Freshly harvested cells were stained with chicken anti-hTGF- $\beta 1$ IgY, followed by goat anti-chicken IgG Alexa 488. High levels of TGF- $\beta 1$ were detected in (a) thioglycollate-elicited peritoneal ( 3 days old) and (b) LPS-elicited alveolar ( 2 days old) macrophages, but not in (c) resident peritoneal macrophages, (d) resident alveolar macrophages, or thioglycollate-elicited peritoneal macrophages (TPM $\phi$ 's) with (e) secondary antibody alone and (f) with isotype control. (g) Lavage supernatants from resident (unstimulated) lungs or peritonea had small amounts of TGF- $\beta 1$, while LPS-stimulated lungs and thioglycollate-stimulated peritonea had high levels of TGF- $\beta 1$ upon harvest. ${ }^{*} P<0.05, n \geq 8, \pm$ SD. 


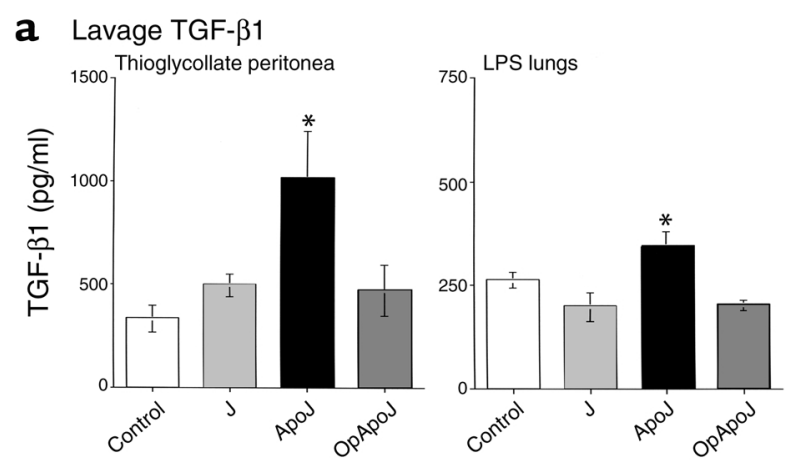

b Phagocytic index

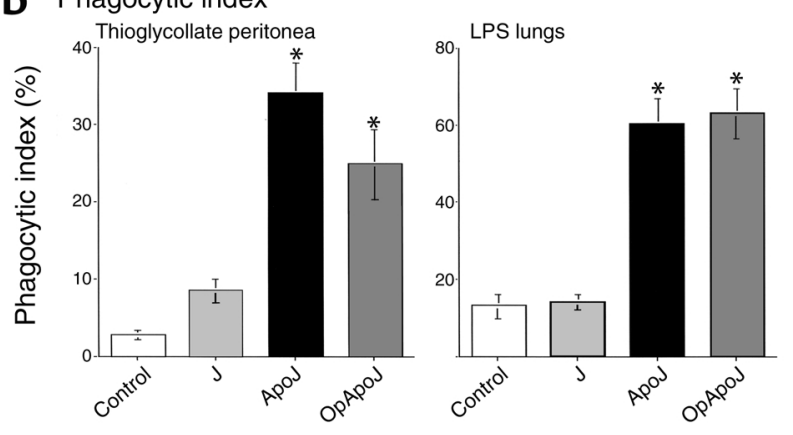

c

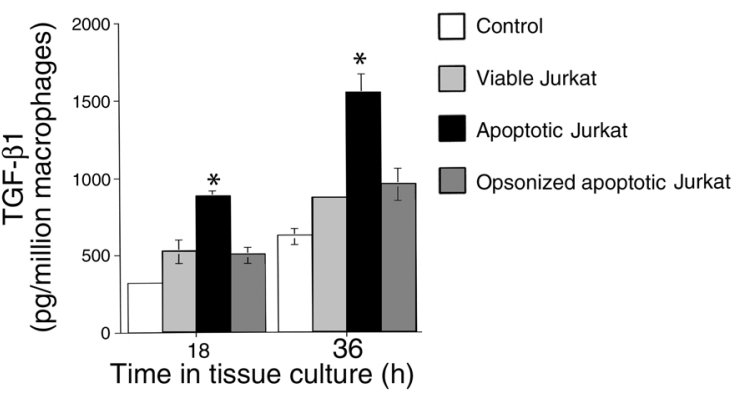

into the lungs or thioglycollate into the peritoneum), the lavaged cells contained enhanced cell-associated TGF- $\beta$ (Figure 1, a-f). Similarly, only small amounts of TGF- $\beta 1$ were detected by ELISA in freshly harvested lavage fluid from resident lungs or peritonea, and these amounts were significantly increased after inflammatory lesions were induced (Figure 1g).

TGF- $\beta 1$ secretion after in vivo instillation of apoptotic cells into inflamed but not naive peritonea or lungs. To examine the effect of the exposure of apoptotic cells to an inflamed lesion, apoptotic or viable Jurkat $\mathrm{T}$ cells and HBSS were injected in vivo into thioglycollate-stimulated peritonea (stimulated 3 days prior, i.e., at a point of maximal recruitment of macrophages). Analysis of peritoneal lavage fluids taken 4 hours later by ELISA showed a further increase in free TGF- $\beta 1$ in mice injected with apoptotic Jurkat $T$ cells beyond the high basal levels in mice injected with HBSS alone (Figure 2a), while viable cell injection did not alter the TGF- $\beta 1$ level from the base line. Forty million cells provided an estimated 1:3 macrophage/apoptotic cell ratio and resulted in more consistent induction of TGF- $\beta 1$ than did lower numbers of cells (data not shown). At 4 hours, almost all apoptotic cells were cleared and apoptotic

\section{Figure 2}

In vivo secretion ofTGF- $\beta 1$ in inflamed peritonea and lungs is increased by apoptotic cell clearance. After intraperitoneal or endotracheal instillation of HBSS alone (control), viable Jurkat $T$ cells $(J)$, apoptotic Jurkat T cells (ApoJ), or opsonized apoptotic Jurkat T cells (OpApoJ) into LPS-stimulated lungs (2 days old) and thioglycollate-stimulated peritonea ( 3 days old), lavage supernatants collected after 4 hours and 1 hour, respectively, of incubation were assayed for TGF- $\beta 1$ by ELISA. (a) ApoJ induced TGF- $\beta 1$ when compared with control, while J and OpApoJ did not. (b) Phagocytic index ( $\mathrm{PI}$ = number of apoptotic bodies/200 macrophages $\times 100$ ) of peritoneal or bronchoalveolar lavage fluid cytospins showed low uptake in the control and $\mathrm{J}$, and increased PI for both ApoJ and OpApoJ. (c) The TPM $\phi$ 's were isolated and cultured after in vivo instillation of cells; induction of TGF- $\beta 1$ in the macrophages treated with apoptotic Jurkat $T$ cells persisted for 18 and 36 hours in tissue culture, when compared with that in viable and opsonized apoptotic Jurkat T cells. (a) ${ }^{*} P<0.05, n=6, \pm$ SD; (b) ${ }^{*} P<0.05, n \geq 12, \pm \mathrm{SD} ;(\mathbf{c}){ }^{*} P<0.05, n \geq 10, \pm \mathrm{SD}$.

bodies were apparent in macrophages (Figure 2b). Similarly, instillation of apoptotic cells, when compared with viable cells and HBSS, into lungs stimulated with LPS for 24-48 hours induced TGF- $\beta 1$ release (obtained by bronchoalveolar lavage 2 hours after instillation) (Figure 2a). Due to increased surface area and alveolar spaces, 20 million cells were chosen after a dose titration yielded consistent effects on TGF- $\beta 1$ secretion, and histologic lung sections confirmed the presence of apoptotic cells in the alveolar spaces (data not shown). The increased TGF- $\beta 1$ secretion induced by apoptotic cells correlated with uptake of these cells into macrophages as assessed by an increased phagocytic index (Figure 2b). In contrast, lavages of noninflamed peritonea or lungs exhibited low levels of TGF- $\beta 1$ that remained unchanged by exposure to apoptotic cells (data not shown). Macrophages from the lavage of thioglycollate-stimulated peritonea were isolated (after in vivo injection of apoptotic cells) and continued to secrete an enhanced amount of TGF- $\beta 1$ at 18 and 36 hours in tissue culture (Figure 2c).

Macrophages as a major source for the TGF- $\beta 1$. Macrophages were the only cells that contained detectable preformed TGF- $\beta 1$ in free cell suspensions of lavage fluids (Figure 1, a-f). Furthermore, cultured nonmacrophages (i.e., nonadherent cells) secreted essentially no TGF- $\beta 1$ into tissue culture media (data not shown). Thus, in this system, macrophages may be a major source of the TGF- $\beta 1$ obtained by the lavage.

Release of preformed TGF- $\beta$ and requirement for de novo protein synthesis. The increase in free TGF- $\beta$ in the inflamed peritonea was seen within 30 minutes after the instillation of apoptotic cells and corresponded with a concomitant decrease in cell-associated protein (Figure 3, a-c). In addition, having established that elicited macrophages were a major source of TGF- $\beta 1$ in the peritoneal lavage, we used thioglycollate-elicited peritoneal macrophages (TPM $\phi$ 's) to determine whether de novo protein synthesis was required. Cycloheximide $(5 \mu \mathrm{g} / \mathrm{ml})$ added 1 hour prior to addition of apoptotic Jurkat $\mathrm{T}$ cells completely inhibited the release 

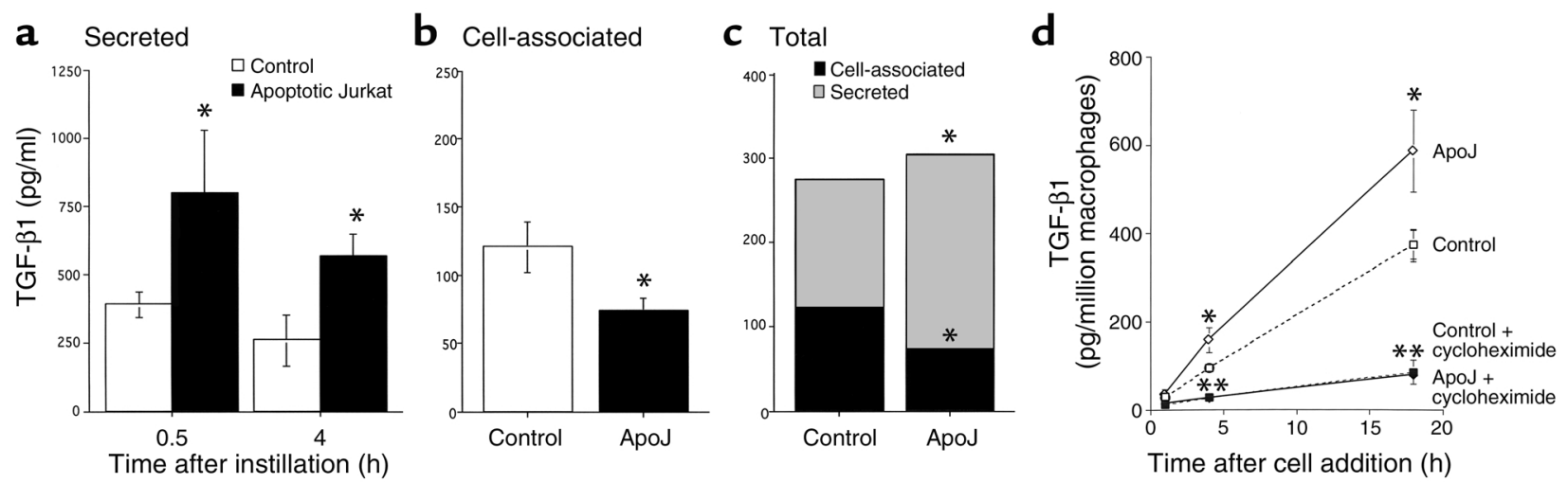

Figure 3

In vivo TGF- $\beta 1$ induction resulted from increased release and de novo synthesis. (a) The increase in TGF- $\beta 1$ secretion in thioglycollate-stimulated peritoneum was seen in 30-minute lavages after in vivo instillation of apoptotic Jurkat $T$ cells (ApoJ) and was more pronounced than in the 4-hour lavages. (b) TPM $\phi$ cell-associated TGF- $\beta 1$ at 1 hour was reduced after in vivo instillation of ApoJ. (c) Total (secreted + cellassociated) TGF- $\beta 1$ remained constant. ${ }^{*} P<0.05, n=8, \pm$ SD. (d) In vitro secretion of TGF- $\beta 1$ by TPM $\phi$ 's was increased after addition of apoptotic Jurkat T cells (ApoJ) compared with media alone (control) at 4 and 18 hours $\left({ }^{*} P<0.05\right)$. TGF- $\beta 1$ secretion in both control and ApoJ-treated macrophages was markedly inhibited by preincubation with cycloheximide $(5 \mu \mathrm{g} / \mathrm{ml})$ for 1 hour. ${ }^{*} P<0.001, n \geq 13, \pm \mathrm{SD}$.

of TGF- $\beta 1$ into the medium (Figure $3 \mathrm{~d}$ ), indicating that de novo protein synthesis is required. The data support a model in which apoptotic cells in vivo induce both the release of preformed TGF- $\beta$ and its de novo synthesis and secretion.

Active TGF- $\beta 1$. Since the ELISA assay detects only active TGF- $\beta 1$, the proportion of TGF- $\beta 1$ that was activated in vivo was determined by directly measuring samples without preactivation (acid activation of samples to $\mathrm{pH} 2-3$ will allow measurement of total TGF- $\beta 1$ [latent + active]). Active TGF- $\beta 1$ levels in peritoneal lavage fluids were increased after apoptotic cell instillation (Figure 4), indicating potential physiological importance for this TGF- $\beta 1$ induction.

Requirement for specific apoptotic cell recognition in the induction of TGF- $\beta$. Because viable Jurkat T cells did not elicit the TGF- $\beta 1$ response seen with apoptotic cells, the TGF- $\beta 1$ induction is suggested to be specific for apoptotic cell clearance systems (Figure 2a). However, because viable cells are inefficiently phagocytosed (32, 33) (Figure 2), the specificity for apoptotic cell clearance versus any phagocytic mechanism needed to be further demonstrated. With this aim, apoptotic Jurkat $\mathrm{T}$ cells were opsonized with mouse anti-human CD45 IgG prior to in vivo instillation, to initiate interaction via $\mathrm{Fc} \gamma$ receptors rather than by apoptotic cell recognition systems. Although opsonized apoptotic cells were cleared as efficiently as apoptotic cells (Figure 2 b), opsonization completely abrogated the increased TGF- $\beta 1$ induction by apoptotic cells in both thioglycollate-stimulated peritoneum and the LPS-stimulated lungs (Figure 2a).

Requirement for surface PS in apoptotic cell induction of TGF- $\beta 1$. We have recently suggested that exposed PS is crucial in the recognition and uptake of apoptotic cells and subsequent production of TGF- $\beta 1$ (4). To examine this requirement in vivo, the human monomyelocyte cell line PLB-985 was employed since it has been shown to not express PS on the surface during ultraviolet- induced apoptosis (31). Buffer alone, viable or apoptotic PLB cells, and apoptotic Jurkat $\mathrm{T}$ cells were instilled into thioglycollate-stimulated peritonea. In contrast to apoptotic Jurkat $T$ cells (which express surface PS), apoptotic PLB cells failed to induce TGF- $\beta 1$ compared with controls (HBSS and viable cells) (Figure $5 b$ ) in spite of equal clearance (Figure 5a). To further confirm that PS is crucial in the induction of TGF- $\beta 1$, the phospholipid was deliberately introduced into the outer leaflet of the surface membrane of the apoptotic PLB cells by phospholipid transfer (31). Apoptotic PLB cells expressing surface PS induced TGF- $\beta 1$, while unmodified apoptotic PLB cells or apoptotic PLB cells treated with a control phospholipid, phosphatidylcholine (PC), did not (Figure 6a). Finally, to demonstrate that PS and its recognition may be sufficient for TGF- $\beta 1$ induction, PS liposomes, PC liposomes, and PBS alone were instilled into 48-hour-old LPS-treated

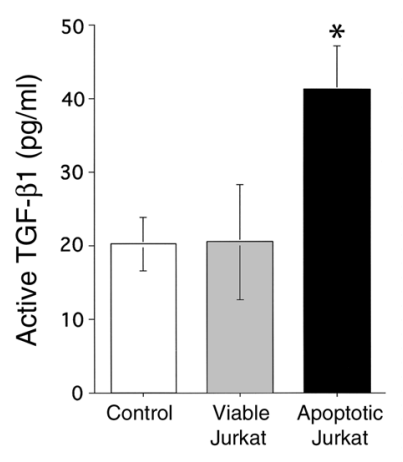

\section{Figure 4}

Active TGF- $\beta 1$ in lavage fluids. Thioglycollate-stimulated peritonea were instilled with media alone (control), and viable or apoptotic Jurkat $T$ cells. Lavage fluids obtained 1 hour later were assayed for TGF- $\beta 1$ by ELISA without preactivation to determine active TGF- $\beta 1$ levels. Apoptotic Jurkats significantly increased active TGF- $\beta 1$ level compared with viable cells and control. ${ }^{*} P<0.05, n \geq 12, \pm \mathrm{SD}$. 

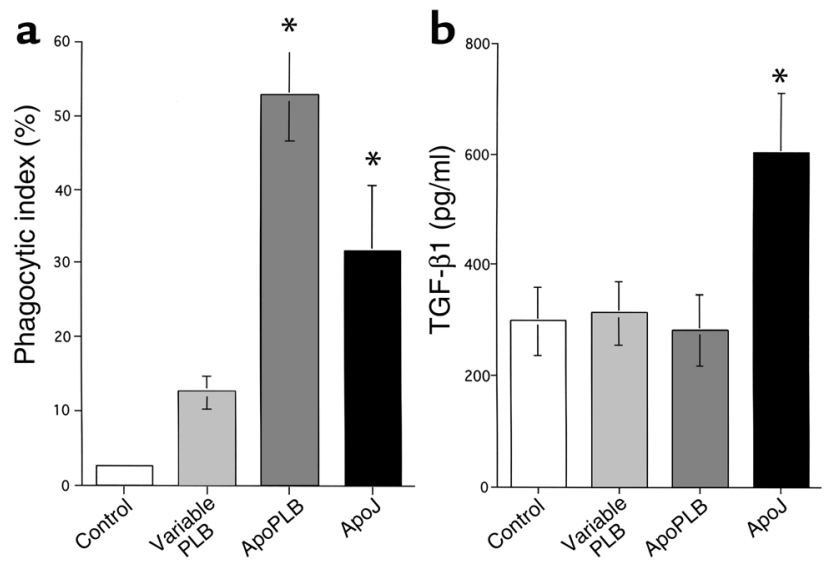

Figure 5

In vivo TGF- $\beta 1$ induction by PLB-985 cells. Viable PLB or apoptotic PLB cells (ApoPLB) and apoptotic Jurkat T cells (ApoJ) were injected into thioglycollate-stimulated peritonea. In the lavage fluid and cells obtained 1 hour later, (a) phagocytic indexes were comparable in the ApoPLB and Apol groups. (b) Viable PLB and ApoPLB cells failed to induce TGF- $\beta 1$, in comparison with ApoJ. ${ }^{*} P<0.02, n \geq 10, \pm$ SD.

lungs. PS liposomes, but not those containing only PC, induced TGF- $\beta 1$ (Figure $6 \mathrm{~b}$ ), although not as dramatically as did intact cells.

Reduction of proinflammatory mediators after instillation of apoptotic cells. In addition to TGF- $\beta 1$, selected cytokines and chemokines were measured by ELISA after in vivo exposure to apoptotic cells. When thioglycollate-stimulated peritonea or LPS-stimulated lungs were lavaged 2-4 hours after instillation of viable or apoptotic Jurkat $\mathrm{T}$ cells, the cytokines and chemokines, TNF- $\alpha, \mathrm{MIP}_{2}$, KC, MCP-1, or IL-10, were no different from those in lungs instilled with apoptotic or viable cells or HBSS alone (data not shown). By contrast, when examined 1 , 3 , and 5 days after cell instillation, significant suppression of proinflammatory mediators was seen at 24 hours. There was marked reduction in TNF- $\alpha, \mathrm{MIP}_{2}$, and KC (Figure 7a), but not MCP-1 or IL-10 (Figure 7b), in the BALF of mice that were exposed to apoptotic cells compared with mice exposed to viable cells and buffer alone. The levels in all groups rapidly declined after 2 days, and the differences were not significant at later time points. Of note, IL-10 was minimally present and may even have been increased at day 5 (not significant). Reduction in inflammatory cells after instillation of apoptotic cells. The BAL cell counts were also measured. Total cells were significantly reduced at 1,3 , and 5 days after instillation, in the mice given apoptotic Jurkat $\mathrm{T}$ cells compared with those given buffer alone or viable cells (Figure 8). This reduction resulted from a marked decrease in neutrophils by days $1-3$, followed by a decrease in lymphocytes from days $3-5$, and finally by a decrease in macrophages at day 5 (Figure 9).

Histological lung sections at days 1 and 3 also confirmed the BALF findings. H\&E sections of lungs fixed with paraformaldehyde after lavage revealed significant reduction in parenchymal infiltrates and intra-alveolar cells in the lungs instilled with apoptotic Jurkat $\mathrm{T}$ cells compared with those instilled with buffer alone at day 1 (Figure 10a) and day 3 (Figure 10b).

Resolution of inflammation is specific for apoptotic cell clearance and is mediated by TGF- $\beta 1$. To show that the resolution of inflammation is specific for apoptotic cell clearance systems, apoptotic cells were opsonized with anti-CD45 IgG1. Day 1 was chosen because it presented the largest difference in neutrophils counts. The reductions in BALF total and neutrophil counts were completely abrogated by opsonization (Figure 11). Furthermore, to confirm that this increased resolution of inflammation was mediated by apoptotic cell induction of TGF- $\beta 1$, goat anti-TGF- $\beta 1$ neutralizing IgG was coinstilled with the apoptotic Jurkat $T$ cells. The anti-TGF- $\beta 1$ antibody completely reversed reduction in the total cell and neutrophil counts by apoptotic cells, while isotype control and anti-TGF- $\beta 1$ antibody with buffer had no effect (Figure 12). The observation suggested that the anti-inflammatory changes are specific for apoptotic cell clearance mechanism and are mediated by induction of TGF- $\beta 1$.

\section{Discussion}

This study demonstrates that direct in vivo instillation of apoptotic cells into inflammatory lesions leads to accelerated resolution of inflammation, most likely mediated by increased production of TGF- $\beta 1$. Based on previous observation of increased TGF- $\beta 1$ and an associated decrease in proinflammatory mediator produc-
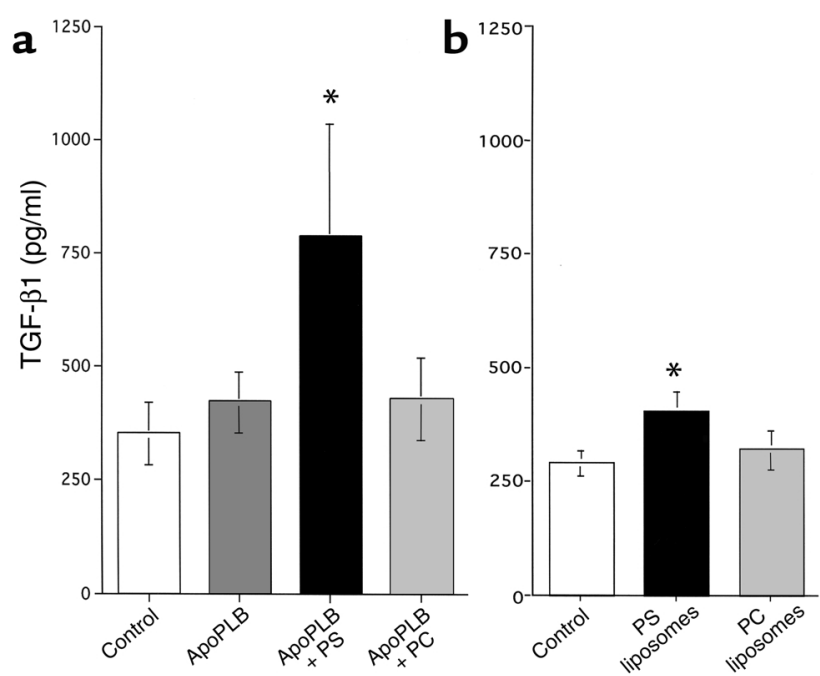

\section{Figure 6}

In vivo TGF- $\beta 1$ secretion in thioglycollate-stimulated peritoneum after instillation of apoptotic PLB-985 cells (ApoPLB) expressing phospholipid PS or PC in the outer leaflet of the plasma membrane. The peritonea were lavaged 1 hour after instillation of cells and TGF- $\beta 1$ determined by ELISA. (a) ApoPLB that expressed PS (ApoPLB + PS) induced TGF- $\beta 1$ when compared with HBSS (control), while unmodified ApoPLB (ApoPLB) or ApoPLB expressing PC (ApoPLB + PC) did not. ${ }^{*} P<0.05, n \geq 9, \pm \mathrm{SD}$. (b) In vivo TGF- $\beta 1$ secretion in LPS-stimulated lungs after instillation of buffer (control), or PS or PC liposomes. TGF- $\beta 1$ in BALF obtained 1 hour later was induced by PS liposomes above control levels, but not by PC liposomes. ${ }^{*} P<0.05, n \geq 12, \pm$ SD. 

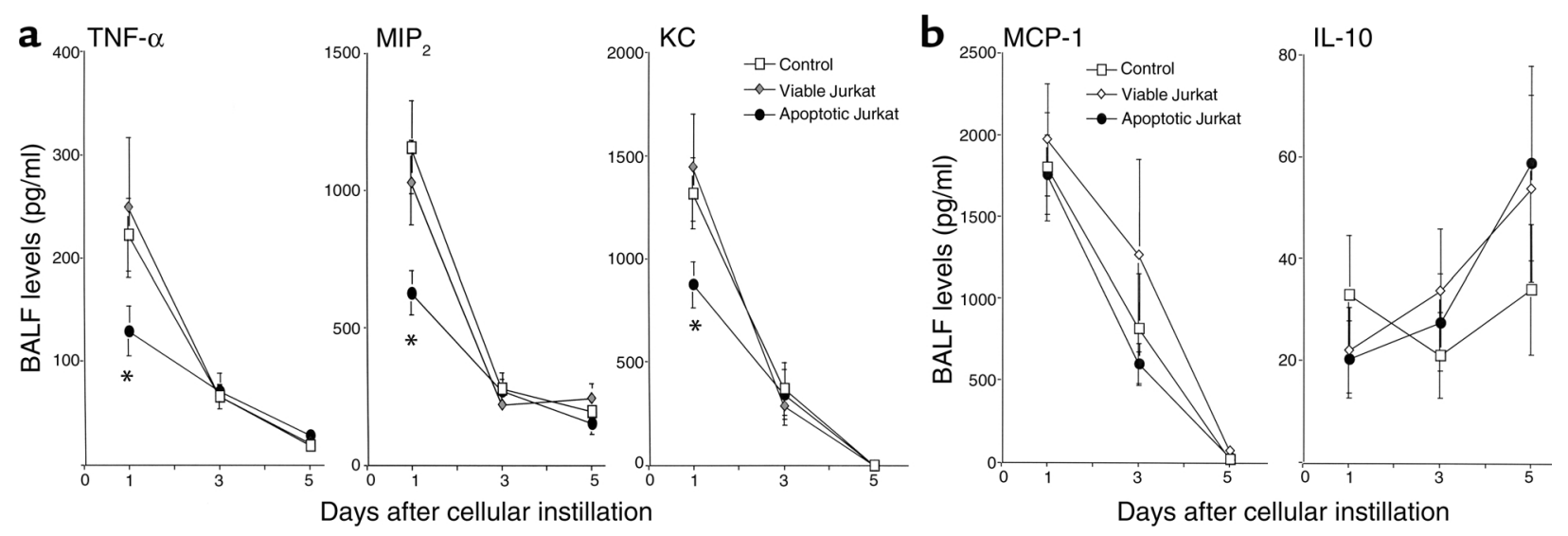

Figure 7

Cytokine and chemokine levels in BAL fluids from LPS-stimulated lungs detected by ELISA. One day after in vivo instillation of HBSS, viable Jurkat T cells, or apoptotic Jurkat T cells, apoptotic cells reduced TNF- $\alpha$, MIP2, and KC levels (a), but not MCP-1 and IL-10 levels (b). ${ }^{*} P<0.05, n \geq 25, \pm \mathrm{SD}$. Levels continued to decline but no significant differences were found at days 3 and 5 .

tion from macrophages when stimulated by in vitro uptake of apoptotic cells (16), we examined here the effects of in vivo apoptotic cell clearance on inflammation. Because of the difficulty in determining rates and degrees of endogenous apoptotic cell generation and removal during an acute inflammatory reaction, the response to deliberate addition of a bolus of new apoptotic cells was examined. While apoptotic neutrophils are likely the dominant cells being removed endogenously, this cell type was avoided because of the potential for introducing additional proinflammatory proteases (34), unaccounted sources of TGF- $\beta 1(18,20)$, and exogenous neutrophils that would interfere with using neutrophils as a marker of inflammation. We thus used Jurkat $\mathrm{T}$ cells for this investigation, because they neither contain nor produce detectible TGF- $\beta 1$. Furthermore, we initially focused on the early response to apoptotic cell instillation to allow comparisons between viable and apoptotic Jurkat $\mathrm{T}$ cells (i.e., before the viable cells themselves undergo apoptosis in the inflammatory environment).

TGF- $\beta 1$ was minimally produced in quiescent states but was significantly increased in inflammatory lesions, such as thioglycollate-stimulated peritonea and LPSstimulated lungs (Figure 1). Here, we have demonstrated that in vivo clearance of apoptotic Jurkat $\mathrm{T}$ cells led to further induction of TGF- $\beta 1$ from this already high basal level in inflammatory lesions (Figure 2a). Active TGF- $\beta$ was also increased (Figure 4 ), suggesting potential physiological importance. The small amounts of active material consistently found in both our in vitro and our in vivo experiments concur with recent reports (35-37) and explain the careful regulation necessary for TGF- $\beta$ 's diverse effects. Furthermore, because TGF- $\beta 1$ is activated at the cellular surface $(24,27,38)$ and/or may be bound to matrix in the tissue, the soluble activity may underestimate the actual local activity levels. The mechanisms by which TGF- $\beta$ is activated are beyond the scope of this project, but the inflammatory lesion itself is likely to provide numerous candidates for TGF- $\beta$ activation, including a variety of proteases and oxidants (39-42), in addition to natural activators such as plasmin/thrombospondin/CD36 (43-45) or the $\alpha_{v} \beta_{6}$ integrin on pulmonary epithelial cells (46).

The major source of the TGF- $\beta 1$ among lavageable cells appeared to be the macrophages since only these both contained preformed TGF- $\beta 1$ and continued to secrete TGF- $\beta 1$ when isolated and cultured in vitro. Microscopic evidence of apoptotic bodies in the macrophages supports the concept that these scavengers are triggered to secrete TGF- $\beta 1$ by apoptotic cell ingestion. It seems likely that previous exposure to endogenous apoptotic cells or cell debris in the inflammatory lesion may have contributed to the high basal TGF- $\beta 1$ level (Figure 1). The persistence in TGF- $\beta 1$ induction by the macrophages also indicated that in

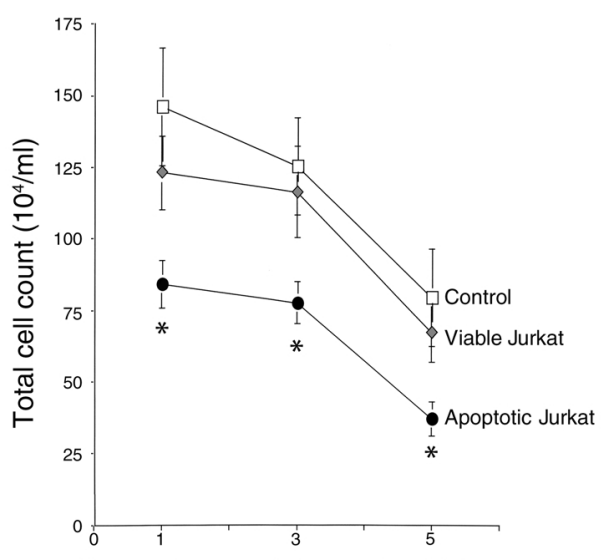

Days after apoptotic cell instillation

\section{Figure 8}

Reduction in BALF total cell counts. Total cell counts in BALF from LPS-stimulated lungs after in vivo instillation of HBSS, viable Jurkat T cells, or apoptotic Jurkat $T$ cells. Apoptotic cells resulted in reduction of total cell counts at days 1,3 , and 5 compared with controls (buffer alone or viable cells). ${ }^{*} P<0.05, n \geq 25$, \pm SD. 


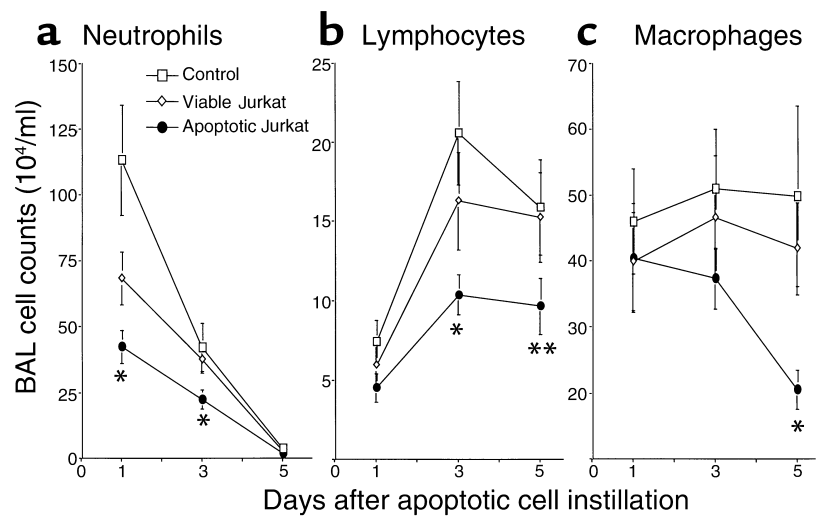

Figure 9

Reduction in BALF inflammatory cells. Cell differential in BALF from LPS-stimulated lungs 1,3 , and 5 days after in vivo instillation of HBSS (control) or viable or apoptotic Jurkat T cells. (a) Neutrophils were reduced at days 1-3, (b) lymphocytes were reduced at days 3 and 5 , and (c) macrophages were decreased by day $5 .{ }^{*} P<0.05$, ${ }^{*} P<0.07, n \geq 25, \pm \mathrm{SD}$.

vivo triggering by apoptotic cells was significant and sustained (Figure $2 \mathrm{c}$ ). Finally, additional TGF- $\beta 1$ contribution from tissue cells, particularly those in the epithelium, and ECM storage may not have been accounted for or accessed by the lavage fluids; these sources may have been affected either by direct interaction with apoptotic cells or by autocrine/paracrine induction of TGF- $\beta 1$ (47).

The immediate increase in TGF- $\beta 1$ occurred within 30 minutes and appeared, in part, to result from release of preformed TGF- $\beta$ from the cells (Figure 3 , a-c). Further induction of TGF- $\beta 1$ was inhibited by cycloheximide in vitro, showing that de novo protein synthesis was also occurring (Figure 3d). These results demonstrated an efficient biphasic response to apoptotic cells: an early, immediate release and later, sustained increased protein synthesis of TGF- $\beta 1$.

Specificity for TGF- $\beta 1$ induction for apoptotic cell recognition systems was suggested, since viable Jurkat
$\mathrm{T}$ cells did not induce TGF- $\beta 1$ when compared with apoptotic cells. Furthermore, in spite of comparable phagocytosis, opsonization of apoptotic Jurkats (to induce clearance via Fc $\gamma$ receptor ligation) abrogated induction of TGF- $\beta 1$ by the apoptotic cells (Figure 2).

Since surface PS recognition and ligation by the PSR has been shown to be important in the uptake of apoptotic cells, the role of PS in the induction of TGF- $\beta 1$ in vivo was examined. By use of a cell line that does not express surface PS during apoptosis, PLB-985, evidence was presented to support a role for specific PS recognition in the in vivo induction of TGF- $\beta$. Thus apoptotic PLB-985 cells were unable to initiate TGF- $\beta$ generation (Figure 5) unless their membranes were first reconstituted with PS (Figure 6a). In addition, direct instillation of PS-containing liposomes was able to stimulate production of TGF- $\beta 1$, although not as effectively as whole apoptotic cells. Optimal engagement of the PSR by PS-expressing apoptotic cells seems to require a second tethering ligand (48) that would not be present on the PS liposome. This may explain the relatively less effective stimulation seen with the isolated PS liposome latter in vivo (Figure 6b) and in vitro (data not shown). These results indicate that PS, and by inference PS receptors, play a critical role in the anti-inflammatory responses to apoptotic cells and may also participate in normal resolution of inflammation.

The TGF- $\beta 1$ production in response to inflammatory insult concurred with published reports of in vitro and in vivo research $(18,49,50)$, but its role is controversial. Classically, TGF- $\beta 1$ is thought to be an important anti-inflammatory mediator, in that TGF- $\beta 1$-null mice (51) and mice deficient in various TGF- $\beta 1$ receptors and activators (46) exhibit persistent inflammation. Recent data $(52,53)$, however, suggest that TGF- $\beta 1$ inhibition, using integrin $\beta 6$-null mice and a TGF- $\beta$ receptor chimera, protects from the inflammation seen in acute lung injury. Hence, we sought to clarify the effects of apoptotic cell clearance, and the subsequent production of TGF- $\beta 1$ and inflammatory mediated products.

\section{Figure 10}

Reduction in inflammation in the lungs. LPS-stimulated lung sections from 1 and 3 days after in vivo apoptotic Jurkat $T$ cell instillation were fixed and stained with $\mathrm{H} \& \mathrm{E}$. The most severely inflamed areas are shown for (a) day 1 after instillation of HBSS (control) and apoptotic Jurkat $T$ cells (ApoJ), and (b) day 3 after instillation of HBSS (control) and apoptotic Jurkat T cells (ApoJ).
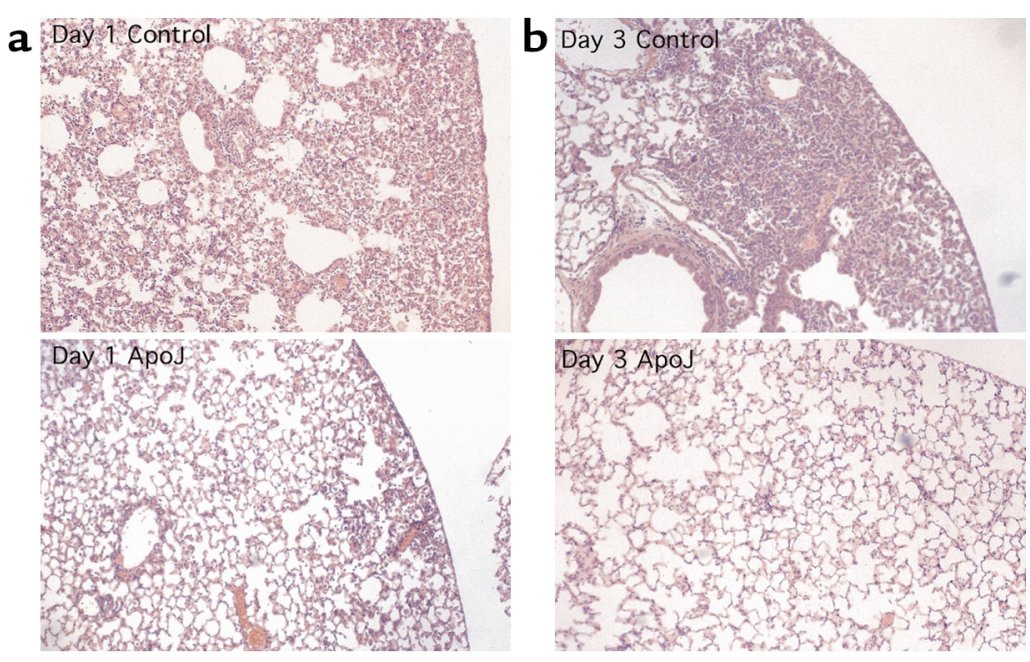

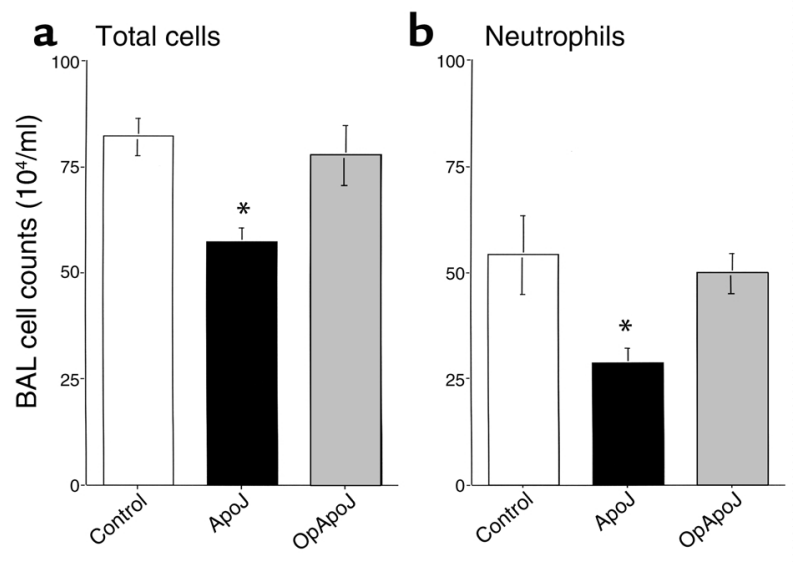

Figure 11

Opsonization reversed the anti-inflammatory effect of apoptotic cell clearance. Apoptotic Jurkat $\mathrm{T}$ cells were opsonized with mouse anti-human CD45 IgG prior to instillation into LPS-stimulated lungs. Opsonization completely reversed the reduction in BALF total cell (a) and neutrophil (b) counts seen one day after apoptotic cell clearance. ${ }^{*} P<0.05, n \geq 15, \pm \mathrm{SD}$.

Critically, in vivo instillation and clearance of apoptotic cells into LPS-induced pneumonitis resulted in a marked reduction in intra-alveolar total cell counts (Figure 8 ). An early reduction in intra-alveolar neutrophils was responsible for this decrease at days 1-3 after instillation (Figure 9). Interestingly, the later reduction in lymphocytes and macrophages suggests that apoptotic cell clearance may exhibit a general suppression of inflammation, perhaps as a consequence of reducing the earlier granulocyte accumulation. The increased resolution of inflammation was also confirmed by lung histology showing improved interstitial inflammatory changes after clearance of apoptotic cells (Figure 10).

Finally, evidence was provided that the resolution of inflammation was specific for apoptotic cell clearance and mediated by TGF- $\beta 1$. In contrast to apoptotic cells, viable cells did not result in a significant antiinflammatory effect. In addition, at the time point when reductions in cell counts and neutrophils were most impressive (day 1), the anti-inflammatory effect of apoptotic cells was prevented by opsonization with anti-CD45 to initiate $\mathrm{Fc} \gamma$ receptor-mediated cell uptake (Figure 11). Similarly, coinstillation of neutralizing anti-TGF- $\beta 1$ antibodies (Figure 12) also reversed the anti-inflammatory effect, while control Ig was ineffective. An alternative explanation that immune complexes between TGF- $\beta$ and its antibody actively overcame the inhibition seems unlikely based on low concentrations (in absolute terms) and previous studies on TGF- $\beta 1$ effects in vitro $(4,16,17)$. These findings emphasize that clearance of apoptotic cells within an inflammatory lesion may be crucial in the resolution of inflammation, not only because of preventative housekeeping, but also due to an active antiinflammatory mechanism, mediated by PSR ligation and subsequent TGF- $\beta 1$ induction.
The apoptotic cell instillation reduced the lavageable levels of TNF- $\alpha, \mathrm{MIP}_{2}$, and KC, in keeping with this anti-inflammatory effect. Interestingly, MCP-1 levels were not reduced. A similar finding was made in vitro $(16,17)$ and attributed to a predominance of activator protein-1 (rather than NF- $\mathrm{\kappa B}$ ) in the transcription of MCP-1. IL-10 production in response to apoptotic cells has been reported (54), especially in the presence of serum factors (31). Its levels did not alter in these studies, but its presence could also contribute to increased resolution of inflammation.

In conclusion, clearance of apoptotic cells, by selective induction of TGF- $\beta$, appears to tip the balance toward an active anti-inflammatory state and, thereby, may promote resolution of inflammation. It also seems likely that it is not only intact apoptotic cells that can induce the anti-inflammatory response, since membrane fragments that express PS on their surface may have a similar effect, a concept supported in this study by the effect of direct instillation of PS-containing liposomes. The mechanism of the increased resolution of inflammation is currently under active investigation but is likely caused by the reduction of chemokines and cytokines. The longer-term effects of TGF- $\beta$ production, in response to apoptotic cells during resolution of inflammation, are contributions to wound healing and fibrosis. Thus, a likely role for persistent apoptotic cell recognition and clearance in fibrotic alterations needs to be investigated. On the other hand, since most inflammatory lesions do not progress to fibrosis, it seems likely that, here too, it is an imbalance of homeostatic regulation of cell clearance and TGF- $\beta$ amounts and effects that determines final outcomes.

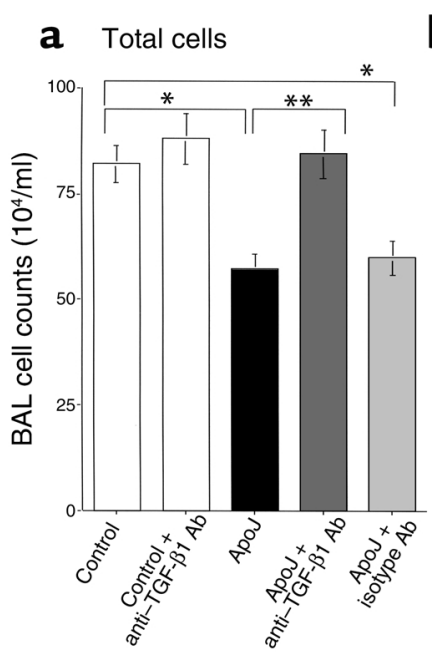

b Neutrophils

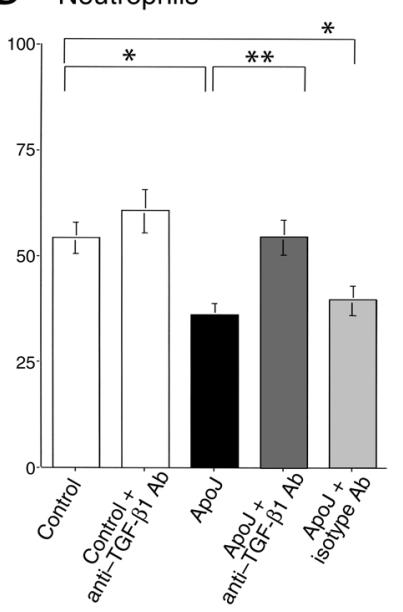

Figure 12

Anti-TGF- $\beta 1$ antibody abrogated the anti-inflammatory effect of apoptotic cell clearance. Goat anti-TGF- $\beta 1$ neutralizing IgG (anti-TGF- $\beta 1 \mathrm{Ab}$ ) or normal goat IgG (Isotype $A b$ ) were coinstilled with media alone (control) or apoptotic Jurkat T cells (ApoJ) into LPS-stimulated lungs. Day 1 BALF showed that the reduction in total cell counts (a) and neutrophils (b) by the ApoJ was completely reversed by opsonization and anti-TGF- $\beta 1$ Ab but not isotype control. Coinstillation of anti-TGF- $\beta 1 \mathrm{Ab}$ into the control group had no significant effect. ${ }^{*} P<0.05,{ }^{*} P<0.05, n \geq 20, \pm$ SD. 


\section{Acknowledgments}

We would like to acknowledge Jay Y. Wescott for preparation of the ELISA and Melissa Rosario for invaluable help with animal care and protocols. Supported by NIH grants HL-34303 (to P.M. Henson) and GM60449 (to V.A. Fadok).

1. Fadok, V.A., et al. 1992. Exposure of phosphatidylserine on the surface of apoptotic lymphocytes triggers specific recognition and removal by macrophages. J. Immunol. 148:2207-2216.

2. Frasch, S.C., et al. 2000. Regulation of phospholipid scramblase activity during apoptosis and cell activation by protein kinase Cdelta. J. Biol. Chem. 275:23065-23073.

3. Bratton, D.L., et al. 1997. Appearance of phosphatidylserine on apoptotic cells requires calcium-mediated nonspecific flip-flop and is enhanced by loss of the aminophospholipid translocase. J. Biol. Chem. 272:26159-26165.

4. Fadok, V.A., et al. 2000. A receptor for phosphatidylserine-specific clearance of apoptotic cells. Nature. 405:85-90.

5. Savill, J. 2000. Apoptosis in resolution of inflammation. Kidney Blood Press. Res. 23:173-174.

6. Fadok, V.A. 1999. Clearance: the last and often forgotten stage of apoptosis. J. Mammary Gland Biol. Neoplasia. 4:203-211.

7. Savill, J., Dransfield, I., Hogg, N., and Haslett, C. 1990. Vitronectin receptor-mediated phagocytosis of cells undergoing apoptosis. Nature. 343:170-173.

8. Platt, N., Suzuki, H., Kurihara, Y., Kodama, T., and Gordon, S. 1996. Role for the class A macrophage scavenger receptor in the phagocytosis of apoptotic thymocytes in vitro. Proc. Natl. Acad. Sci. USA. 93:12456-12460.

9. Platt, N., Suzuki, H., Kodama, T., and Gordon, S. 2000. Apoptotic thymocyte clearance in scavenger receptor class A-deficient mice is apparently normal. J. Immunol. 164:4861-4867.

10. Savill, J., Hogg, N., Ren, Y., and Haslett, C. 1992. Thrombospondin cooperates with CD36 and the vitronectin receptor in macrophage recognition of neutrophils undergoing apoptosis. J. Clin. Invest. 90:1513-1522.

11. Devitt, A., et al. 1998. Human CD14 mediates recognition and phagocytosis of apoptotic cells. Nature. 392:505-509.

12. Gregory, C.D. 2000. CD14-dependent clearance of apoptotic cells: relevance to the immune system. Curr. Opin. Immunol. 12:27-34.

13. Ogden, C.A., et al. 2001. C1q and mannose lectin engagement of cell surface calreticulin and cd91 initiates macropinocytosis and uptake of apoptotic cells. J. Exp. Med. 194:781-796.

14. Cox, G., Crossley, J., and Xing, Z. 1995. Macrophage engulfment of apoptotic neutrophils contributes to the resolution of acute pulmonary inflammation in vivo. Am. J. Respir. Cell Mol. Biol. 12:232-237.

15. Haslett, C. 1999. Granulocyte apoptosis and its role in the resolution and control of lung inflammation. Am. J. Respir. Crit. Care Med. 160:S5-S11.

16. Fadok, V.A., et al. 1998. Macrophages that have ingested apoptotic cells in vitro inhibit proinflammatory cytokine production through autocrine/paracrine mechanisms involving TGF-beta, PGE2, and PAF.J. Clin. Invest. 101:890-898.

17. McDonald, P.P., Fadok, V.A., Bratton, D., and Henson, P.M. 1999. Transcriptional and translational regulation of inflammatory mediator production by endogenous TGF-beta in macrophages that have ingested apoptotic cells. J. Immunol. 163:6164-6172.

18. Massague, J. 1990. The transforming growth factor-beta family. Annu. Rev. Cell Biol. 6:597-641.

19. Massague, J., and Wotton, D. 2000. Transcriptional control by the TGFbeta/Smad signaling system. EMBOJ. 19:1745-1754.

20. Basile, D.P. 1999. The transforming growth factor beta system in kidney disease and repair: recent progress and future directions. Curr. Opin. Nephrol. Hypertens. 8:21-30.

21. Letterio, J.J., and Roberts, A.B. 1998. Regulation of immune responses by TGF-beta. Annu. Rev. Immunol. 16:137-161.

22. Border, W.A., and Noble, N.A. 1994. Transforming growth factor beta in tissue fibrosis. N. Engl. J. Med. 331:1286-1292.

23. de Caestecker, M.P., Piek, E., and Roberts, A.B. 2000. Role of transforming growth factor-beta signaling in cancer. J. Natl. Cancer Inst. 92:1388-1402.

24. Munger, J.S., et al. 1997. Latent transforming growth factor-beta: structural features and mechanisms of activation. Kidney Int. 51:1376-1382.

25. Mangasser-Stephan, K., and Gressner, A.M. 1999. Molecular and functional aspects of latent transforming growth factor-beta binding protein: just a masking protein? Cell Tissue Res. 297:363-370.

26. Saharinen, J., and Keski-Oja, J. 2000. Specific sequence motif of 8-Cys repeats of TGF-beta binding proteins, LTBPs, creates a hydrophobic interaction surface for binding of small latent TGF-beta. Mol. Biol. Cell. 11:2691-2704

27. Gleizes, P.E., et al. 1997. TGF-beta latency: biological significance and mechanisms of activation. Stem Cells. 15:190-197.
28. Chong, H., Vodovotz, Y., Cox, G.W., and Barcellos-Hoff, M.H. 1999. Immunocytochemical localization of latent transforming growth factorbeta1 activation by stimulated macrophages. J. Cell. Physiol. 178:275-283.

29. Tucker, K.A., Lilly, M.B., Heck, L., Jr., and Rado, T.A. 1987. Characterization of a new human diploid myeloid leukemia cell line (PLB-985) with granulocytic and monocytic differentiating capacity. Blood. 70:372-378.

30. Savige, J.A., Saverymuttu, S.H., and Pinching, A.J. 1984. A functional comparison of IIIindium-labeled elicited peripheral blood neutrophils and peritoneal neutrophils in the rat. Clin. Exp. Immunol. 58:737-744.

31. Fadok, V.A., de Cathelineau, A., Daleke, D.L., Henson, P.M., and Bratton, D.L. 2001. Loss of phospholipid asymmetry and surface exposure of phosphatidylserine is required for phagocytosis of apoptotic cells by macrophages and fibroblasts. J. Biol. Chem. 276:1071-1077.

32. Hu, B., Sonstein, J., Christensen, P.J., Punturieri, A., and Curtis, J.L. 2000 Deficient in vitro and in vivo phagocytosis of apoptotic $T$ cells by resident murine alveolar macrophages. J. Immunol. 165:2124-2133.

33. Licht, R., Jacobs, C.W., Tax, W.J., and Berden, J.H. 1999. An assay for the quantitative measurement of in vitro phagocytosis of early apoptotic thymocytes by murine resident peritoneal macrophages. J. Immunol. Methods. 223:237-248.

34. Fadok, V.A., Bratton, D.L., Guthrie, L., and Henson, P.M. 2001. Differential effects of apoptotic versus lysed cells on macrophage production of cytokines: role of proteases. J. Immunol. 166:6847-6854.

35. Lawrence, D.A. 1991. Identification and activation of latent transforming growth factor beta. Methods Enzymol. 198:327-336.

36. Nunes, I., Shapiro, R.L., and Rifkin, D.B. 1995. Characterization of latent TGF-beta activation by murine peritoneal macrophages. J. Immunol. 155:1450-1459

37. Yu, Q., and Stamenkovic, I. 2000. Cell surface-localized matrix metalloproteinase-9 proteolytically activates TGF-beta and promotes tumor invasion and angiogenesis. Genes Dev. 14:163-176.

38. Mazzieri, R., Munger, J.S., and Rifkin, D.B. 2000. Measurement of active TGF-beta generated by cultured cells. Methods Mol. Biol. 142:13-27.

39. Vodovotz, Y., et al. 1999. Regulation of transforming growth factor beta1 by nitric oxide. Cancer Res. 59:2142-2149.

40. Barcellos-Hoff, M.H., Derynck, R., Tsang, M.L., and Weatherbee, J.A. 1994 Transforming growth factor-beta activation in irradiated murine mammary gland. J. Clin. Invest. 93:892-899.

41. Barcellos-Hoff, M.H., and Dix, T.A. 1996. Redox-mediated activation of latent transforming growth factor-beta 1. Mol. Endocrinol. 10:1077-1083.

42. Wu, S.M., Patel, D.D., and Pizzo, S.V. 1998. Oxidized alpha2-macroglobulin (alpha2M) differentially regulates receptor binding by cytokines/growth factors: implications for tissue injury and repair mechanisms in inflammation. J. Immunol. 161:4356-4365.

43. Khalil, N., Corne, S., Whitman, C., and Yacyshyn, H. 1996. Plasmin regulates the activation of cell-associated latent TGF-beta 1 secreted by rat alveolar macrophages after in vivo bleomycin injury. Am. J. Respir. Cell Mol. Biol. 15:252-259.

44. Yehualaeshet, T., et al. 1999. Activation of rat alveolar macrophage-derived latent transforming growth factor beta- 1 by plasmin requires interaction with thrombospondin-1 and its cell surface receptor, CD36. Am. J. Pathol. 155:841-851.

45. Yehualaeshet, T., et al. 2000. A CD36 synthetic peptide inhibits bleomycininduced pulmonary inflammation and connective tissue synthesis in the rat. Am. J. Respir. Cell Mol. Biol. 23:204-212.

46. Munger, J.S., et al. 1999. The integrin alpha v beta 6 binds and activates latent TGF beta 1: a mechanism for regulating pulmonary inflammation and fibrosis. Cell. 96:319-328.

47. Van Obberghen-Schilling, E., Roche, N.S., Flanders, K.C., Sporn, M.B., and Roberts, A.B. 1988. Transforming growth factor beta 1 positively regulates its own expression in normal and transformed cells. J. Biol. Chem. 263:7741-7746

48. Hoffmann, P.R., et al. 2001. Phosphatidylserine (PS) induces PS receptormediated macropinocytosis and promotes clearance of apoptotic cells. $J$ Cell Biol. 155:649-659.

49. Khalil, N., Bereznay, O., Sporn, M., and Greenberg, A.H. 1989. Macrophage production of transforming growth factor beta and fibroblast collagen synthesis in chronic pulmonary inflammation. J. Exp. Med. 170:727-737.

50. Khalil, N., Whitman, C., Zuo, L., Danielpour, D., and Greenberg, A. 1993. Regulation of alveolar macrophage transforming growth factor-beta secretion by corticosteroids in bleomycin-induced pulmonary inflammation in the rat. J. Clin. Invest. 92:1812-1818.

51. Shull, M.M., et al. 1992. Targeted disruption of the mouse transforming growth factor-beta 1 gene results in multifocal inflammatory disease. Nature. 359:693-699.

52. Pittet, J.F., et al. 2001. TGF-beta is a critical mediator of acute lung injury. J. Clin. Invest. 107:1537-1544.

53. Sheppard, D. 2001. Pulmonary fibrosis: a cellular overreaction or a failure of communication? J. Clin. Invest. 107:1501-1502.

54. Groux, H., et al. 1997. A CD4+ T-cell subset inhibits antigen-specific T-cell responses and prevents colitis. Nature. 389:737-742. 